\title{
Energy migration processes in phosphate nanocrystals: size and dimensionality dependence
}

\author{
N.V. Kononets, V.V. Seminko, P.O. Maksimchuk, I.I. Bespalova, \\ V.K. Klochkov, and Yu.V. Malyukin \\ Institute for Scintillation Materials, National Academy of Sciences of Ukraine, \\ 60 Nauky Ave., Kharkiv 61072, Ukraine \\ E-mail: seminko@isma.kharkov.ua
}

Received November 11,2017, published online March 27, 2018

\begin{abstract}
Peculiarities of electronic excitation energy migration in phosphate nanocrystals with three-dimensional $\left(\mathrm{EuPO}_{4}\right)$ and one-dimensional $\left(\mathrm{EuP}_{3} \mathrm{O}_{9}\right)$ arrangement of regular ions under variation of concentration of both energy traps $\left(\mathrm{Nd}^{3+}\right.$ ions) and scattering centres $\left(\mathrm{La}^{3+}\right.$ ions) are discussed in the paper. Processes of energy migration in both $\mathrm{EuPO}_{4}$ and $\mathrm{EuP}_{3} \mathrm{O}_{9}$ nanocrystals are phonon-assisted ones due to absence of resonance between energy levels of adjacent $\mathrm{Eu}^{3+}$ ions. The distance of energy migration for both $\mathrm{EuPO}_{4}$ and $\mathrm{EuP}_{3} \mathrm{O}_{9}$ nanocrystals was found to be equal to tens of nanometres, however, for $\mathrm{EuPO}_{4}$ nanocrystals energy migration leads to stronger quenching of $\mathrm{Eu}^{3+}$ luminescence. For $10 \mathrm{~nm} \mathrm{EuPO}_{4}$ nanocrystals sufficient hampering of energy migration is observed due to the depletion of the low-energy phonon spectrum as a result of the phonon confinement effect.
\end{abstract}

PACS: 78.55.-m Photoluminescence, properties and materials.

Keywords: energy migration, phosphates, nanocrystals, luminescence spectra.

\section{Introduction}

Development of biological labels for visualization of intra-cellular processes has recently made sufficient advances providing biologists with high number of various materials ranging from fluorescent dyes to inorganic nanoparticles. A number of newly developed biomedical techniques such as visualization of deep tumors and x-ray photodynamic therapy require scintillating RE-doped inorganic nanoparticles $[1,2]$. Using the mechanisms of transport of electronic excitation energy within the system of rare-earth (RE) ions, energy absorbed by nanoparticle can be delivered either to photosensitizer molecules chemically or physically absorbed on the surface of nanoparticle, or to other rare-earth ions which IR luminescence can deeply penetrate into biological tissue. So, the peculiarities of migration of electronic excitation energy over sublattice of regular RE ions should be taken into account for development of more efficient nanomaterials for these needs.

Phosphate nanoparticles have recommended themselves as the excellent materials for biomedical applications [3-5]. For instance, calcium phosphate nanoparticles have shown good biocompatibility and absence of toxicity being easily dissolved in lysosomes after the cellular intake [6,7].

Both arrangement of regular RE ions [8,9] and size of nanocrystal can provide the sufficient modification of the process of electronic excitation energy migration. For the sufficient small sizes the nanocrystal surface can play a role of scattering impurities providing the localization of electronic excitation inside the "cage" and in this way leading to increase of the probability of electronic excitation energy capture by traps [10,11]. Also, in our last studies for $\operatorname{Pr}^{3+}$-doped silicate [12], vanadate [13], and phosphate [14] nanocrystals, we have observed that dopant ions with radii different from the ones of regular ions are preferably localized in the near-surface layer of nanoparticle. So, for effective delivery of energy absorbed within nanoparticle to luminescence centers the distance of energy migration must be comparable with the size of nanocrystal itself. From all RE-doped crystals, only the ones containing $\mathrm{Eu}^{3+}, \mathrm{Tb}^{3+}$ and $\mathrm{Gd}^{3+}$ as regular ions have shown the energy migration over sufficient distances (1 nm or more) [15-17], while for other RE ions luminescence is quenched effectively by crossrelaxation mechanism $[18,19]$ and any sufficient migration of energy cannot be expected.

In this paper we have investigated the migration of electronic excitation energy in $\mathrm{Nd}^{3+}$ and $\mathrm{La}^{3+}$-doped phosphate nanoparticles $\left(\mathrm{EuPO}_{4}\right.$ and $\left.\mathrm{EuP}_{3} \mathrm{O}_{9}\right)$ with different arrangements of regular $\mathrm{Eu}^{3+}$ ions (three-dimensional for $\mathrm{EuPO}_{4}$ and one-dimensional for $\mathrm{EuP}_{3} \mathrm{O}_{9}$ ) and sizes. Migration of electronic excitation energy in some 
phosphate crystals and micropowders were investigated previously in the number of papers [20,21]. However, recent studies have shown that the mechanisms of excitation energy relaxation in RE-doped nanoparticles can differ sufficiently from the ones for bulk crystals leading, for instance, to modification of kinetics of luminescence decay [22], absorption/emission from high stark components $[23,24]$ and abnormal narrowing of spectral lines [25]. For undoped $\mathrm{EuPO}_{4}$ and $\mathrm{EuP}_{3} \mathrm{O}_{9}$ nanocrystals the processes of energy migration were studied in our previous paper [26]. In this paper, using the variation of the concentrations of $\mathrm{Nd}^{3+}$ and $\mathrm{La}^{3+}$ ions in $\mathrm{EuPO}_{4}$ and $\mathrm{EuP}_{3} \mathrm{O}_{9}$ nanocrystals we have determined the role of both the arrangement of regular $\mathrm{Eu}^{3+}$ ions and nanocrystal size in the formation of specific features of the migration of electronic excitation energy in these nanocrystals.

\section{Experimental}

In order to obtain $100 \mathrm{~nm} \mathrm{EuPO} 4$ and $\mathrm{Eu}_{1-x} \mathrm{La}_{x} \mathrm{PO}_{4}: \mathrm{Nd}^{3+}$ (0.1, $0.7,1.5$ at.\%) nanocrystals $\mathrm{H}_{3} \mathrm{PO}_{4}$ solution $(0.5 \mathrm{~mol} / \mathrm{l})$ was added to $10 \mathrm{ml} \mathrm{EuCl} 3$ solution $(0.5 \mathrm{~mol} / \mathrm{l})$ till $\mathrm{EuPO}_{4}$ precipitation. After centrifugation the precipitate was annealed at $1100^{\circ} \mathrm{C}$ in air during $5 \mathrm{~h}$.

For the synthesis of $10 \mathrm{~nm} \mathrm{EuPO} 4$ nanocrystals colloidal aqueous solutions of rare-earth chloride and sodium tripolyphosphate were used. Sodium tripolyphosphate played the dual role - as the source of $\mathrm{PO}_{4}^{3-}$ anions formed during tripolyphosphate hydrolysis and as stabilizing agent for colloidal nanoparticle. Details of synthesis are described in our previous paper [27].

$\mathrm{EuP}_{3} \mathrm{O}_{9}$ and $\mathrm{Eu}_{1-x} \mathrm{La}_{x} \mathrm{P}_{3} \mathrm{O}_{9}: \mathrm{Nd}^{3+}$ nanocrystals with different concentration of neodymium ions $(0.1,0.7,1.5$ at.\%) were synthesized by solid state method. Europium (III) oxide $\left(\mathrm{Eu}_{2} \mathrm{O}_{3}\right)$, lanthanum (III) oxide $\left(\mathrm{La}_{2} \mathrm{O}_{3}\right)$, neodymium (III) oxide $\left(\mathrm{Nd}_{2} \mathrm{O}_{3}\right)$ and ammonium dihydrophosphate $\left(\mathrm{NH}_{4} \mathrm{H}_{2} \mathrm{PO}_{4}\right)$ taken in required proportions were milled in agate mortar, then heated to $600^{\circ} \mathrm{C}$ with heating speed of $50^{\circ} \mathrm{C} / \mathrm{h}$ and maintained at this temperature for $10 \mathrm{~h}$. Then the powder again was grounded in an agate mortar, and annealed at $1000^{\circ} \mathrm{C}$ for $15 \mathrm{~h}$. Average size of synthesized nanocrystals was $\sim 100 \mathrm{~nm}$.

The purity of crystal phase was controlled by x-ray diffraction (XRD) (Fig. 1). The sizes of nanocrystals were determined using transmission electron microscopy (TEM) and ZetaPALS analyzer (Brookhaven, NY). In the Fig. 2 TEM images of $\mathrm{EuPO}_{4}$ nanocrystals of different sizes are shown.

Luminescence spectra were obtained using spectrofluorimeter based on the grating monochromator, luminescence was excited by the fourth harmonics of YAG:Nd laser $\left(\lambda_{\text {exc }}=266 \mathrm{~nm}\right)$.

The luminescence decay was taken using the timecorrelated single-photon counting (TCSPC) technique. Temperature was varied from 10 to $300 \mathrm{~K}$ using ARS
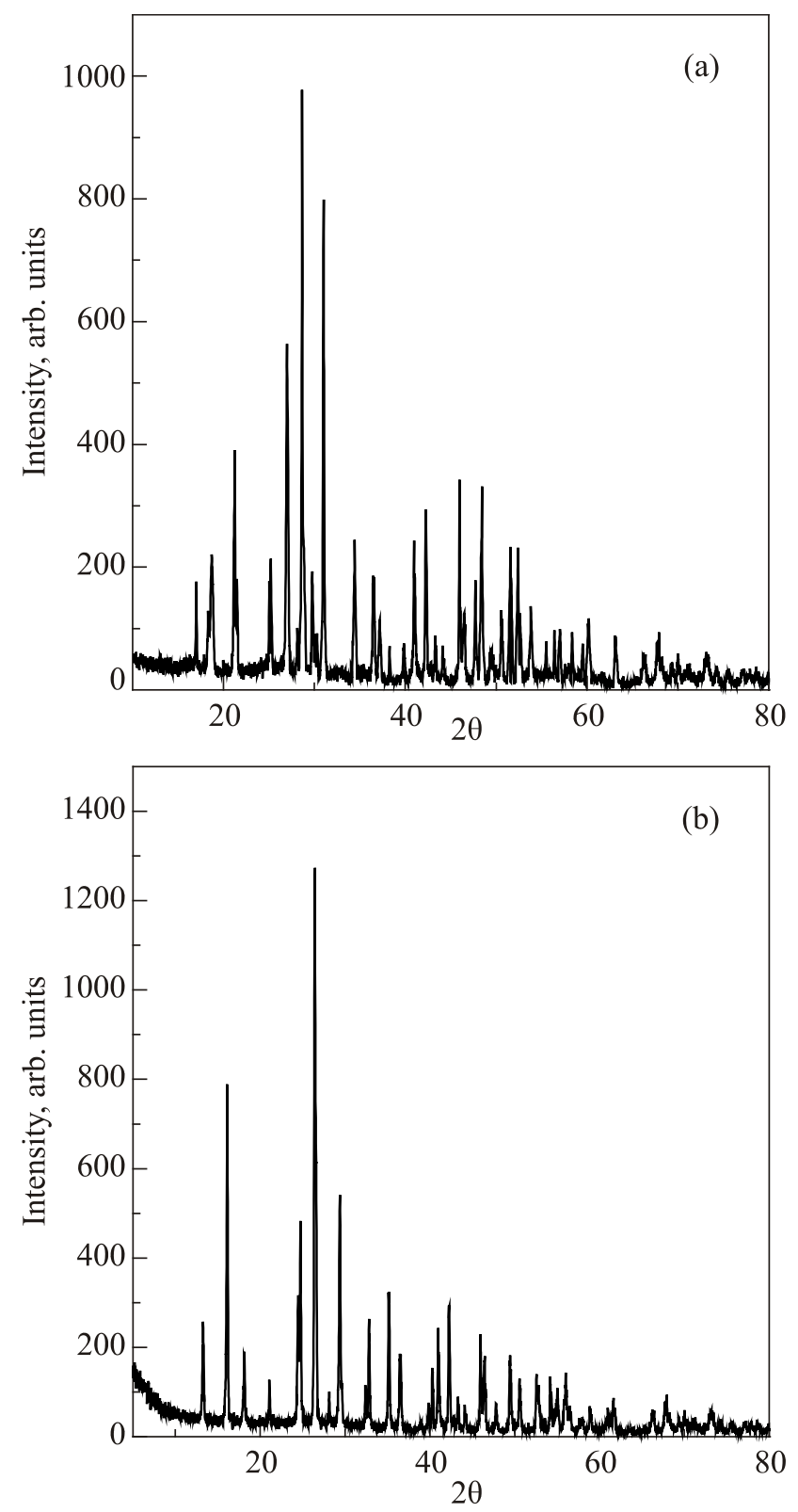

Fig. 1. XRD of $\mathrm{EuPO}_{4}(\mathrm{a})$ and $\mathrm{EuP}_{3} \mathrm{O}_{9}$ (b) nanocrystals.

DE-204AE cryostat with LakeShore 335 temperature controller.

\section{Results and discussion}

The crystal structure of $\mathrm{EuP}_{3} \mathrm{O}_{9}$ is characterized by presence of one-dimensional $\mathrm{Eu}^{3+}$ chains with $\sim 4.2 \AA$ distance between $\mathrm{Eu}^{3+}$ ions in the same chain and $\sim 7.3 \AA$ between chains [28] and previously, in [29] it was shown that energy migration in bulk $\mathrm{EuP}_{3} \mathrm{O}_{9}$ is strongly anisotropic. At the same time, the structure of $\mathrm{EuPO}_{4}$ does not involve any anisotropy in arrangement of regular ions (shortest distance between $\mathrm{Eu}^{3+}$ ions $\sim 3.5 \AA$ ) [30]. In order to compare the peculiarities of electronic excitation energy migration in phosphate nanocrystals with different structures we have used $\mathrm{Nd}^{3+}$-doped mixed $\mathrm{La}_{1-x} \mathrm{Eu}_{x} \mathrm{PO}_{4}$ and $\mathrm{La}_{1-x} \mathrm{Eu}_{x} \mathrm{P}_{3} \mathrm{O}_{9}$ 


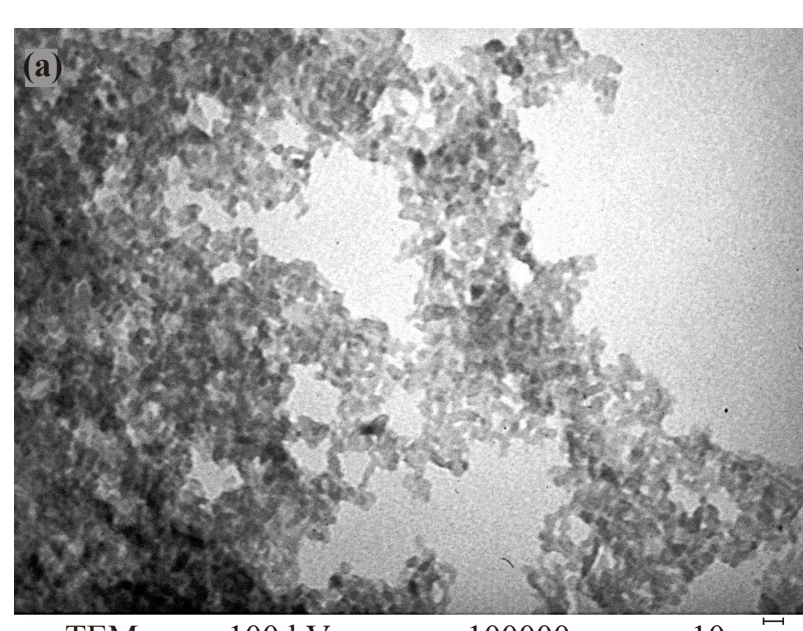

TEM $\quad 100 \mathrm{kV}$ $\times 100000$ $10 \mathrm{~nm}$

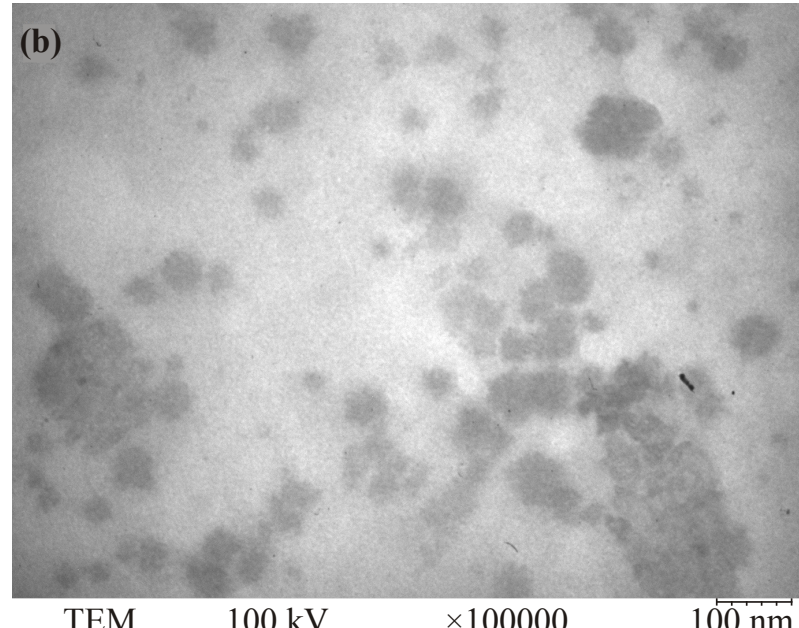

Fig. 2. TEM images of 100 (a) and 10 (b) $\mathrm{nm} \mathrm{EuPO}_{4}$ nanocrystals.

nanocrystals, where $\mathrm{Nd}^{3+}$ ions were used as energy traps, and $\mathrm{La}^{3+}$ ions as scattering centers (energy barriers) (see Fig. 3). For the investigation of the influence of size restriction on the processes of energy migration $100 \mathrm{~nm}$ and $10 \mathrm{~nm} \mathrm{EuPO} 4$ nanocrystals were obtained. Because, in pure $\mathrm{EuP}_{3} \mathrm{O}_{9}$ and $\mathrm{EuPO}_{4}$ nanocrystals energy traps are represented by europium $\left(\mathrm{Eu}^{3+}\right)$ ions with distorted coordination,
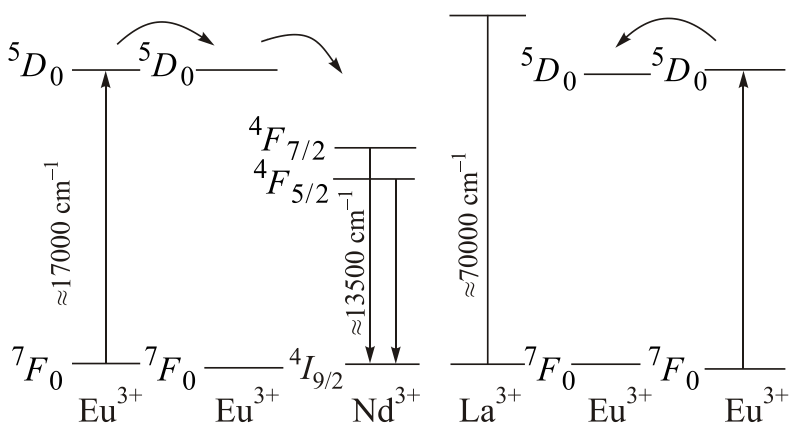

Fig. 3. Scheme of energy levels and possible pathways of energy migration in $\mathrm{Nd}^{3+}$-doped mixed $\mathrm{La}_{1-x} \mathrm{Eu}_{x} \mathrm{PO}_{4}$ and $\mathrm{La}_{1-x} \mathrm{Eu}_{x} \mathrm{P}_{3} \mathrm{O}_{9}$ nanocrystals. which concentration is unknown, doping by $\mathrm{Nd}^{3+}$ ions $(0.1$, 0.7 and 1.5 at.\%) was used for creation of intentionally determined concentrations of energy traps. Variation of $\mathrm{La}^{3+}$ content was used to estimate the distance of energy migration in both types of nanocrystals.

The luminescence spectra of $\mathrm{Nd}^{3+}$-doped (0.1 at.\%) $\mathrm{EuPO}_{4}$ and $\mathrm{EuP}_{3} \mathrm{O}_{9}$ nanocrystals $\left(\lambda_{\text {exc }}=266 \mathrm{~nm}\right)$ are shown in the Fig. 4. The spectra consist of spectral lines corresponding to the characteristic ${ }^{5} D_{0} \rightarrow{ }^{7} F_{J}(J=0,1,2,3)$ transitions of $\mathrm{Eu}^{3+}$ ions (Fig. 4). Spectral lines of $\mathrm{Nd}^{3+}$ ions cannot be observed in the spectra $\left(\mathrm{Nd}^{3+}\right.$ luminescence is in the IR region). For $\mathrm{EuPO}_{4}: \mathrm{Nd}^{3+}$ nanocrystals both temperature and
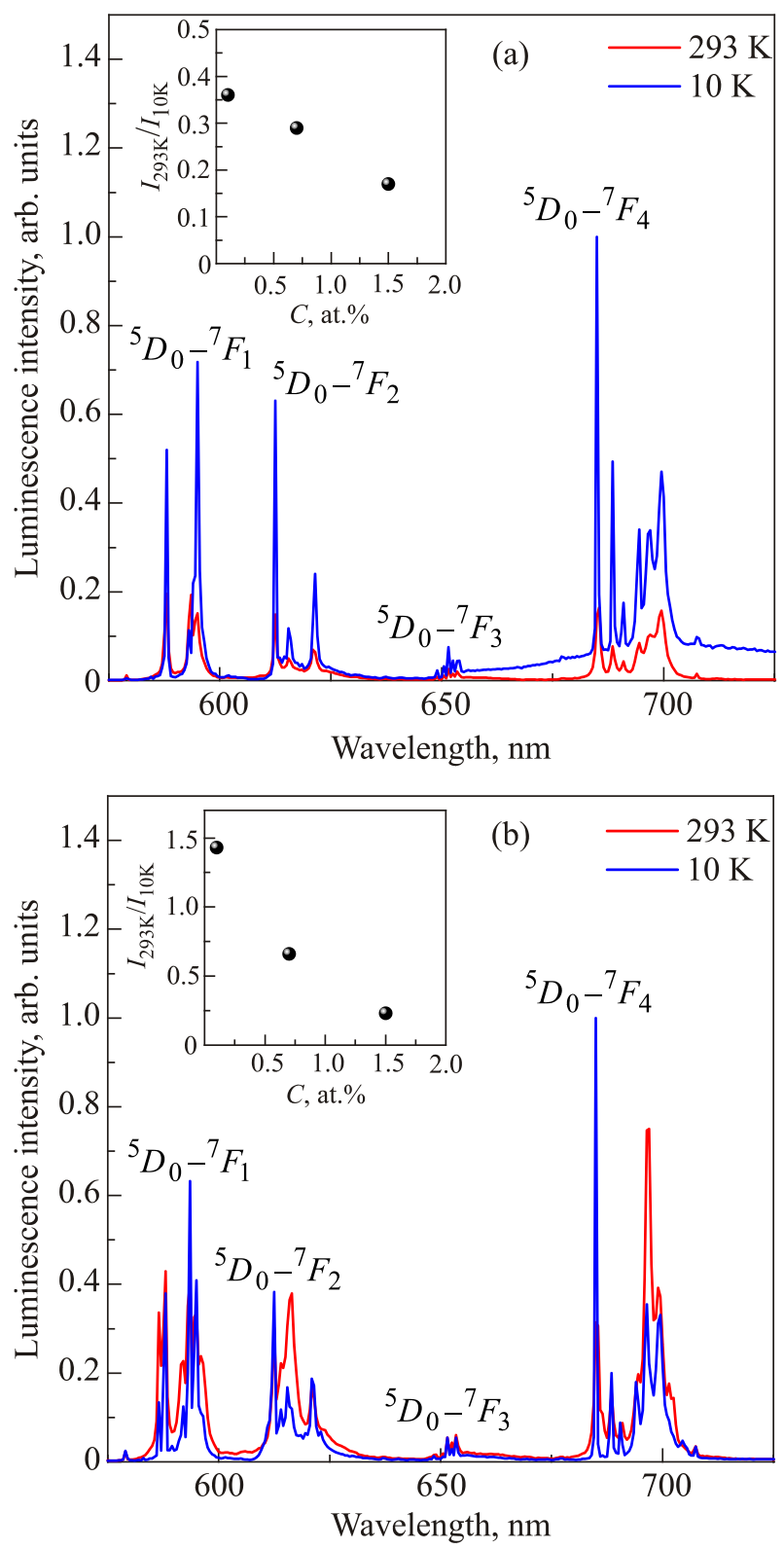

Fig. 4. (Color online) Luminescence spectra of $\mathrm{Nd}^{3+}$-doped (0.1 at.\%) $\mathrm{EuPO}_{4}$ (a) and $\mathrm{EuP}_{3} \mathrm{O}_{9}$ (b) nanocrystals at 10 and $293 \mathrm{~K}\left(\lambda_{\text {exc }}=266 \mathrm{~nm}\right)$. Insets: $\mathrm{Nd}^{3+}$ concentration dependence of $I_{293 \mathrm{~K}} / I_{10 \mathrm{~K}}$ ratio for $\mathrm{EuPO}_{4}$ and $\mathrm{EuP}_{3} \mathrm{O}_{9}$ nanocrystals, respectively. 
$\mathrm{Nd}^{3+}$ concentration increase leads to $\mathrm{Eu}^{3+}$ luminescence quenching due to energy transfer from $\mathrm{Eu}^{3+}$ to $\mathrm{Nd}^{3+}$ ions (Fig. 4(a)). In the insets the changes of $I_{293 \mathrm{~K}} / I_{10 \mathrm{~K}}$ ratio for $\mathrm{EuPO}_{4}$ and $\mathrm{EuP}_{3} \mathrm{O}_{9}$ nanocrystals with variation of $\mathrm{Nd}^{3+}$ concentration are shown, where $I_{10 \mathrm{~K}}$ and $I_{293 \mathrm{~K}}$ are the integrated $\mathrm{Eu}^{3+5} D_{0} \rightarrow F_{J}$ luminescence intensities at 10 and $293 \mathrm{~K}$, respectively. For $\mathrm{Nd}^{3+}$-doped $\mathrm{EuPO}_{4}$ nanocrystals the stronger $\mathrm{Eu}^{3+}$ luminescence quenching is observed as compared to $\mathrm{Nd}^{3+}$-doped $\mathrm{EuP}_{3} \mathrm{O}_{9}$ nanocrystals with the same dopant concentration (for 0.7 at. $\%$ : $I_{293 \mathrm{~K}} / I_{10 \mathrm{~K}} \sim 0.3$ for EuPO$_{4}: \mathrm{Nd}^{3+}$ and $\sim 0.7$ for $\mathrm{EuP}_{3} \mathrm{O}_{9}: \mathrm{Nd}^{3+}$, for 1.5 at. $\%$ : $I_{293 \mathrm{~K}} / I_{10 \mathrm{~K}} \sim 0.15$ for $\mathrm{EuPO}_{4}: \mathrm{Nd}^{3+}$ and $\sim 0.25$ for $\mathrm{EuP}_{3} \mathrm{O}_{9}: \mathrm{Nd}^{3+}$ ). The stronger luminescence quenching for nanocrystals with three-dimensional arrangement of $\mathrm{Eu}^{3+}$ ions can be explained by more effective excitation energy migration in such systems.

More information regarding energy migration parameters in $\mathrm{EuPO}_{4}$ and $\mathrm{EuP}_{3} \mathrm{O}_{9}$ nanocrystals can be obtained from decay curves of ${ }^{5} \mathrm{D}_{0}$ luminescence of $\mathrm{Eu}^{3+}$ ions. Decay curves after $266 \mathrm{~nm}$ excitation were taken in the wide temperature range for $\mathrm{Nd}^{3+}$-doped $(0.1,0.7$ and 1.5 at.\%) $\mathrm{EuPO}_{4}$ and $\mathrm{EuP}_{3} \mathrm{O}_{9}$ nanocrystals. The decay for $\mathrm{Nd}^{3+}$ concentration equal to 0.1 at.\% are shown in the Fig. 5(a) $\left(\mathrm{EuPO}_{4}\right)$ and Fig. 5(b) $\left(\mathrm{EuP}_{3} \mathrm{O}_{9}\right)$. Both temperature and $\mathrm{Nd}^{3+}$ concentration increase led to stronger deviation of decay curves from single-exponential decay law. Time dependences of luminescence intensity in the presence of diffusion-limited energy migration are described by the following expressions: $I=I_{0} \exp \left(-t / \tau_{0}-W t\right)$, where $W$ is proportional to traps concentration $C$ (for three-dimensional energy migration) and $I=I_{0} \exp \left(-t / \tau_{0}-B t^{1 / 3}\right)$, where $B$ is proportional to $C^{2 / 3}$ (for one-dimensional energy migration) [31]. Analysis of decay curves for $\mathrm{EuPO}_{4}$ and $\mathrm{EuP}_{3} \mathrm{O}_{9}$ nanocrystals at different temperatures and $\mathrm{Nd}^{3+}$ concentrations have shown that they are well-fitted by the corresponding decay laws (see insets in Figs. 5(a) and Fig. 5(b)). Energy migration parameters $W$ and $B$ depend both on $\mathrm{Nd}^{3+}$ concentration and temperature, but these dependences for $\mathrm{EuPO}_{4}$ and $\mathrm{EuP}_{3} \mathrm{O}_{9}$ nanocrystals are sufficiently different (see Figs. 6(a) and 6(b)). While for $\mathrm{EuP}_{3} \mathrm{O}_{9}$ nanocrystals at all $\mathrm{Nd}^{3+}$ concentrations $W$ increases only from 10 to $100 \mathrm{~K}$ after which no increase (or even slight decrease) of $W$ is observed, for $\mathrm{EuPO}_{4} W$ increases in the whole temperature range.

Also the change of the values of energy migration parameters with temperature variation is sufficiently different: up to 100 times for $\mathrm{EuPO}_{4}$ and only 1.5 times for $\mathrm{EuP}_{3} \mathrm{O}_{9}$. These differences in temperature dependence confirm that energy migration lead to more effective quenching for $\mathrm{EuPO}_{4}$ nanocrystals than for $\mathrm{EuP}_{3} \mathrm{O}_{9}$ ones in full agreement with the results obtained from luminescence spectra (Fig. 4). This, in turn, can be determined by different mechanisms of energy migration in $\mathrm{EuPO}_{4}$ and $\mathrm{EuP}_{3} \mathrm{O}_{9}$ nanocrystals. For $\mathrm{EuP}_{3} \mathrm{O}_{9}$ the short separation between $\mathrm{Eu}^{3+}$ ions in the same chain favors energy migration via
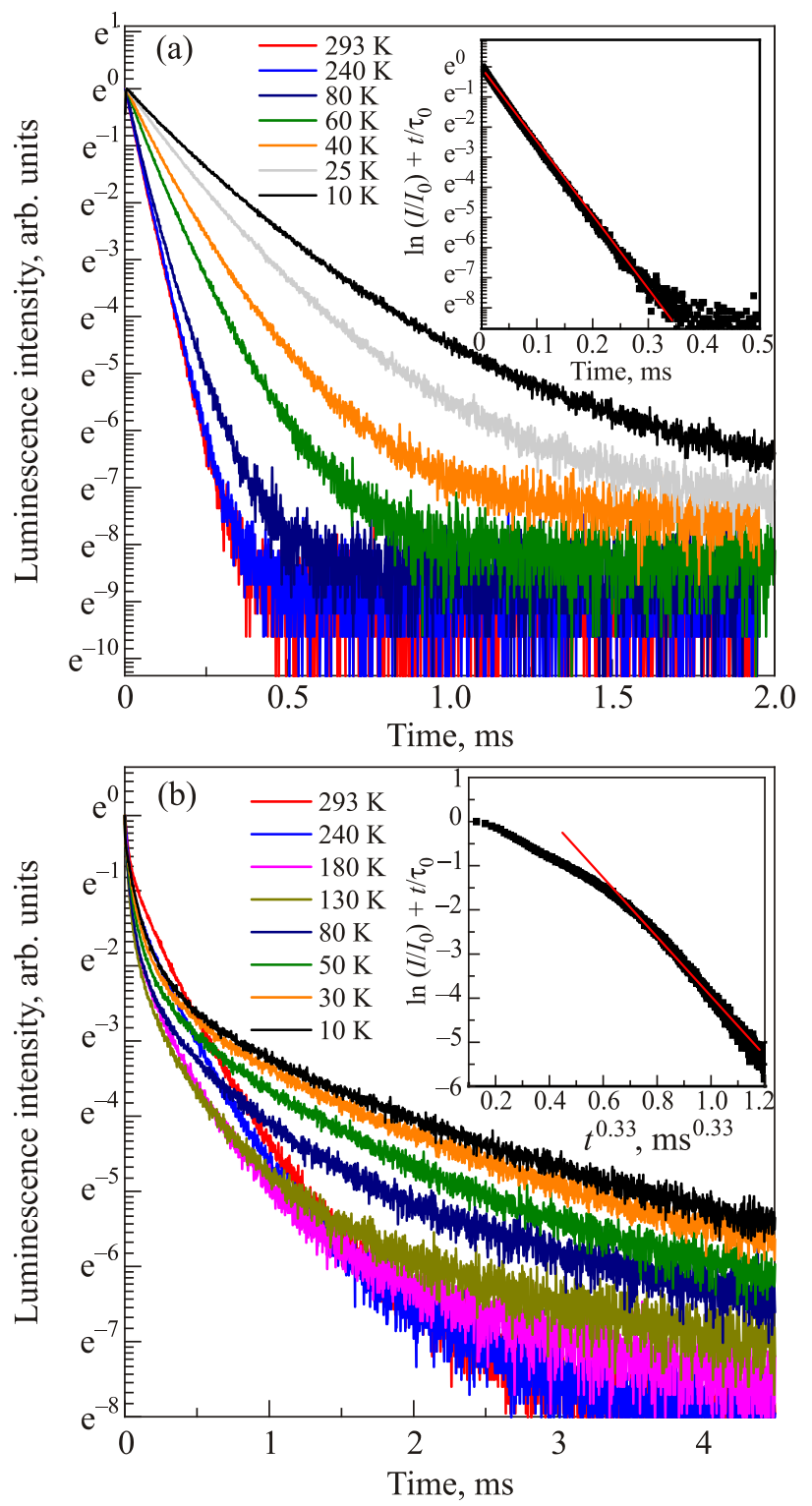

Fig. 5. (Color online) Decay curves of $\mathrm{Nd}^{3+}$-doped (0.1 at.\%) $\mathrm{EuPO}_{4}$ (a) and $\mathrm{EuP}_{3} \mathrm{O}_{9}$ (b) nanocrystals at temperatures from 10 to $293 \mathrm{~K}\left(\lambda_{\text {exc }}=266 \mathrm{~nm}\right)$. Insets: the same decay curves in $\left\{\ln \left(I / I_{0}\right)+t / \tau_{0}, t\right\}\left(\right.$ for $\mathrm{EuPO}_{4}: \mathrm{Nd}^{3+}$ ) and $\left\{\ln \left(I / I_{0}\right)+t / \tau_{0}, t^{0.33}\right\}$ (for $\left.\mathrm{EuP}_{3} \mathrm{O}_{9}: \mathrm{Nd}^{3+}\right)$ coordinates.

exchange interaction involving ${ }_{7}^{5} D_{0} \rightarrow{ }^{7} F_{0}$ transitions (in multipole approximation ${ }^{5} D_{0} \rightarrow{ }^{7} F_{0}$ transitions are absolutely forbidden as $0 \rightarrow 0$ transitions) [15]. Dipole-dipole interactions via ${ }^{5} D_{0} \rightarrow{ }^{7} F_{1}$ transitions cannot be completely ruled out, but even at room temperature, they should not lead to one-dimensional energy migration over any considerable distances. Really, for realization of this mechanism of energy migration, ${ }^{7} F_{1}$ energy levels of high number of adjacent $\mathrm{Eu}^{3+}$ ions must be thermally populated. At $293 \mathrm{~K}$ the quota of ions with thermally populated ${ }^{7} F_{1}$ energy levels is $\sim \exp (-\Delta E / k T)$. The energy difference between ${ }^{7} F_{1}$ and ${ }^{7} F_{0}$ levels $\Delta E \approx 200 \mathrm{~cm}^{-1}$, so at room temperature $\exp (-\Delta E / k T) \approx \exp (-200 / 200) \approx 0.37$. Sure, this quota of 
(a)

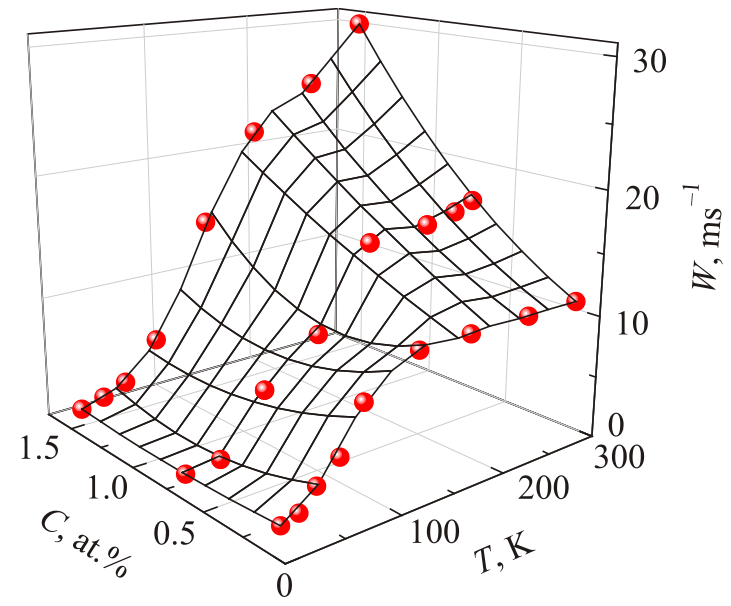

(b)

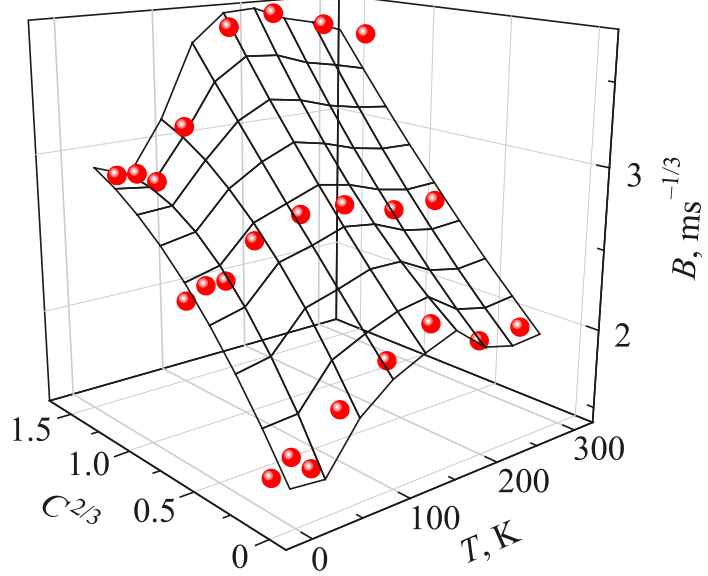

Fig. 6. (Color online) Temperature and $\mathrm{Nd}^{3+}$ concentration dependences of energy migration parameters $W$ and $B$ (described in the text) for $\mathrm{EuPO}_{4}$ (a) and $\mathrm{EuP}_{3} \mathrm{O}_{9}$ (b) nanocrystals, respectively.

ions is insufficient for observing continual one-dimensional migration via dipole-dipole mechanism. So, the role of temperature in energy transfer processes consists only in overcoming the slight energy difference between ${ }^{5} D_{0}$ levels of adjacent $\mathrm{Eu}^{3+}$ ions.

For $\mathrm{EuPO}_{4}$ energy transfer via both multipole (dipoledipole) and exchange interactions is possible. At low temperatures, energy migration is mainly determined by exchange interaction involving ${ }^{5} D_{0} \rightarrow{ }^{7} F_{0}$ transitions, for which the role of temperature is limited to overcoming of small energy mismatch between adjacent $\mathrm{Eu}^{3+}$ ions. At higher temperatures, the thermal population of ${ }^{7} F_{1}$ electronic levels becomes crucial. The quota of ions with thermally populated ${ }^{7} F_{1}$ energy levels at room temperature as well as for $\mathrm{EuP}_{3} \mathrm{O}_{9}$ nanocrystals should be $\approx 0.37$. However, contrary to $\mathrm{EuP}_{3} \mathrm{O}_{9}$ nanocrystals, energy migration in $\mathrm{EuPO}_{4}$ nanocrystals is not limited to only one specific direction, so the dipole-dipole mechanism of energy migration via ${ }^{5} D_{0} \rightarrow{ }^{7} F_{1}$ transitions is possible. In this way, the strong temperature dependence of energy migration in the whole temperature range is observed for $\mathrm{EuPO}_{4}$ nanocrystals.
Distance of energy migration can vary sufficiently depending on the crystal structure. If this distance is comparable with the size of nanocrystal, influence of size restriction on the processes of energy migration can be expected. Presence or absence of such influence can be determined directly by obtaining nanocrystals with different sizes or by incorporation of energy barriers into $\mathrm{Eu}^{3+}$ chains. Decay curves of $\mathrm{La}_{1-x} \mathrm{Eu}_{x} \mathrm{PO}_{4}$ and $\mathrm{La}_{1-x} \mathrm{Eu}_{x} \mathrm{P}_{3} \mathrm{O}_{9}$ nanocrystals with $\mathrm{La}^{3+}$ concentration of $0.1,1,10$ and 50 at. $\%$ and fixed $\mathrm{Nd}^{3+}$ concentration of 0.1 at. $\%$ are shown in the Fig. 7. $\mathrm{La}^{3+}$ ions were supposed to play the same roles in the processes of energy migration as the boundaries of nanocrystal restricting the energy migration.

For $\mathrm{La}_{1-x} \mathrm{Eu}_{x} \mathrm{P}_{3} \mathrm{O}_{9}: \mathrm{Nd}^{3+}$ decay curve at 50 at. $\%$ of $\mathrm{La}^{3+}$ ions was single exponential and no energy transfer was observed. This result agrees well with the previous supposition
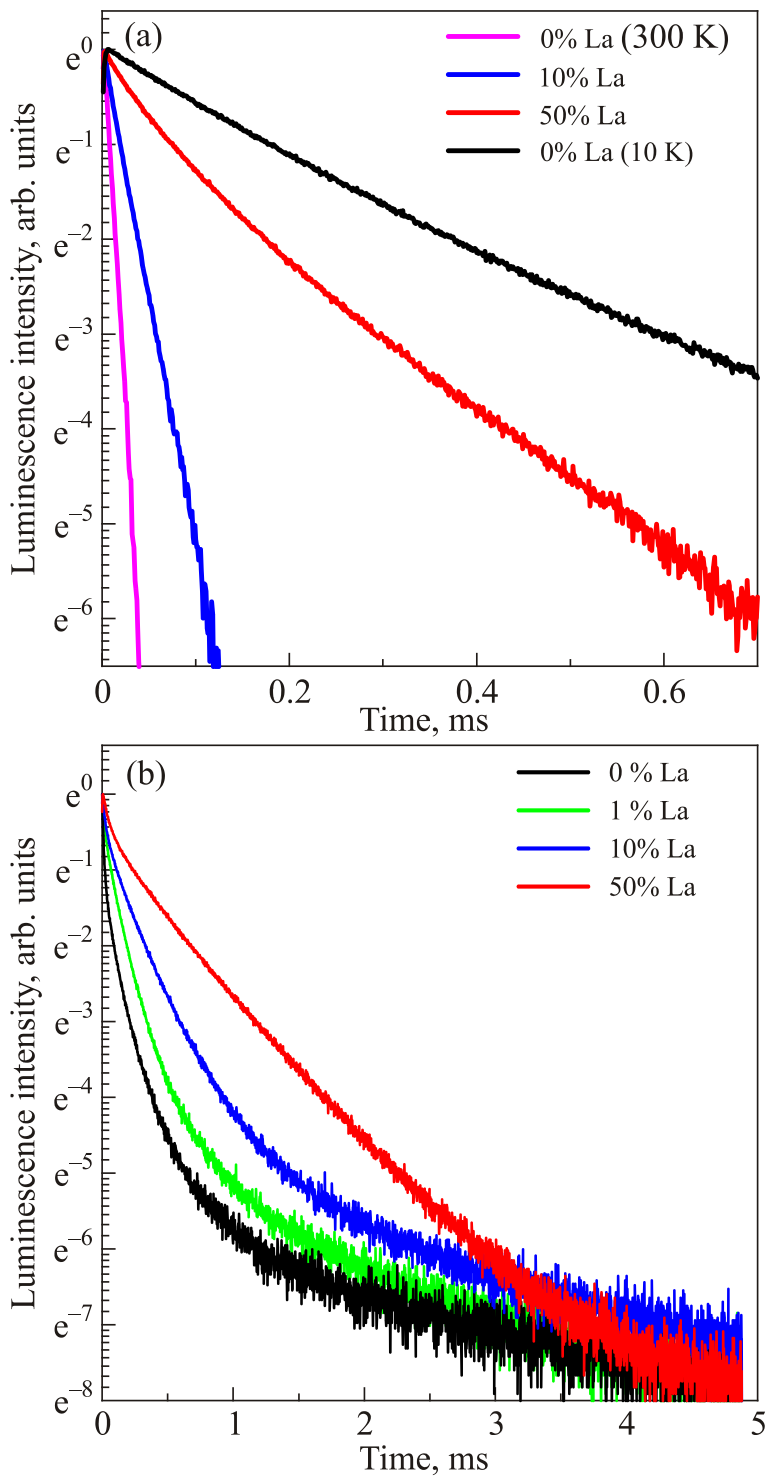

Fig. 7. (Color online) Decay curves of $\mathrm{Nd}^{3+}$-doped (0.1 at.\%) $\mathrm{La}_{1-x} \mathrm{Eu}_{x} \mathrm{PO}_{4}$ (a) and $\mathrm{La}_{1-x} \mathrm{Eu}_{x} \mathrm{P}_{3} \mathrm{O}_{9}$ (b) nanocrystals with different $\mathrm{La}^{3+}$ concentration. 
of exchange (and not dipole-dipole) interaction mediating energy transfer for $\mathrm{EuP}_{3} \mathrm{O}_{9}$. Contrary to $\mathrm{La}_{1-x} \mathrm{Eu}_{x} \mathrm{P}_{3} \mathrm{O}_{9}: \mathrm{Nd}^{3+}$, for $\mathrm{La}_{1-x} \mathrm{Eu}_{x} \mathrm{PO}_{4}: \mathrm{Nd}^{3+}$ decay curve at 50 at. $\%$ of $\mathrm{La}^{3+}$ ions was not single exponential due to possibility of dipole-dipole energy transfer mechanism. Decrease of $\mathrm{La}^{3+}$ content for both $\mathrm{La}_{1-x} \mathrm{Eu}_{x} \mathrm{P}_{3} \mathrm{O}_{9}: \mathrm{Nd}^{3+}$ and $\mathrm{La}_{1-x} \mathrm{Eu}_{x} \mathrm{PO}_{4}: \mathrm{Nd}^{3+}$ leads to deviation of decay curves from exponential law. Decay curves for $\mathrm{EuPO}_{4}: \mathrm{Nd}^{3+}$ and $\mathrm{La}_{0.99} \mathrm{Eu}_{0.01} \mathrm{PO}_{4}: \mathrm{Nd}^{3+}$ coincide, while for $\mathrm{La}_{1-x} \mathrm{Eu}_{x} \mathrm{P}_{3} \mathrm{O}_{9}: \mathrm{Nd}^{3+}$ presence of even 1 at. $\%$ of $\mathrm{La}^{3+}$ ions leads to hampering of energy migration. Taking into account the distance between nearest-neighbor $\mathrm{Eu}^{3+}$ ions (3.5 $\AA$ for $\mathrm{EuPO}_{4}$ and $4 \AA$ for $\mathrm{EuP}_{3} \mathrm{O}_{9}$ ), one can conclude that the distance of energy migration within $\mathrm{Eu}^{3+}$ subsystem for both these structures is $\sim 10 \mathrm{~nm}$ (for $\mathrm{EuP}_{3} \mathrm{O}_{9}$ - few tens $\mathrm{nm}$ ) and variation of the size of nanocrystal would lead to modification of energy migration processes in these lattices.

As the distance of energy migration is comparable with the size of nanocrystal, decrease of the size of nanocrystal can lead to modification of energy migration process. In order to reveal directly the influence of size confinement on the energy transfer processes, $\mathrm{EuPO}_{4}$ nanocrystals of different sizes were obtained. The decay curves for 10 and $100 \mathrm{~nm} \mathrm{EuPO} 4$ nanocrystals at temperature variation are shown in the Fig. 8 (inset). Decrease of the size of nanocrystal leads to shortening of the average distances between initially excited $\mathrm{Eu}^{3+}$ ions and quenching sites (first of all, surface-related defects such as near-surface $\mathrm{Eu}^{3+}$ ions with distorted coordination). So, according to our predictions, more effective quenching of $\mathrm{Eu}^{3+}$ luminescence should be observed. Surprisingly, decrease of the size of nanocrystal from 100 to $10 \mathrm{~nm}$ led to the hampering

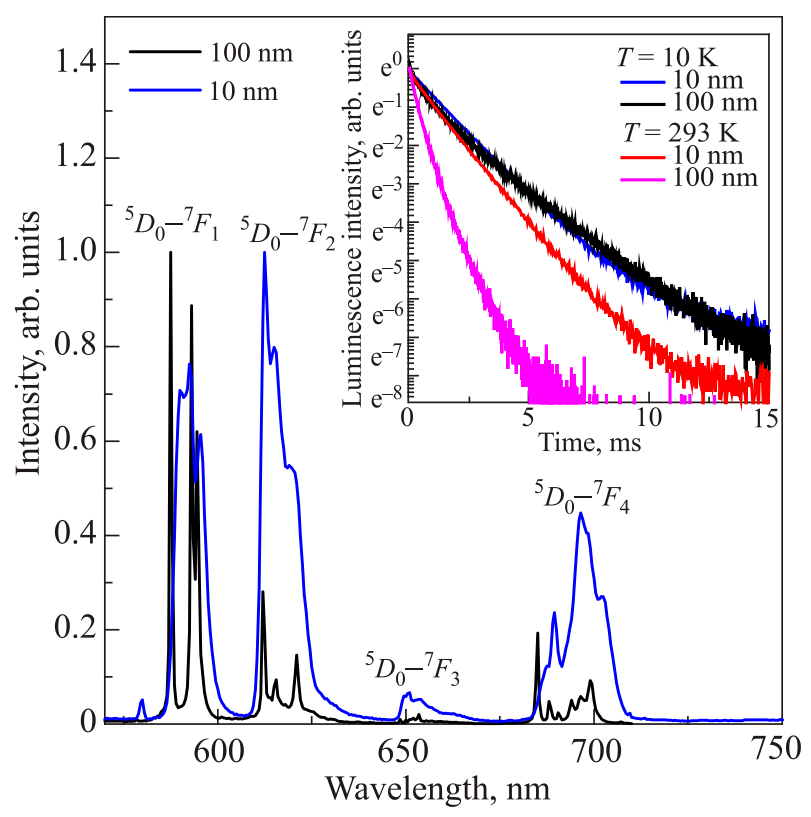

Fig. 8. (Color online) Luminescence spectra of 100 and $10 \mathrm{~nm}$ $\mathrm{EuPO}_{4}$ nanocrystals $(T=10 \mathrm{~K})$. Inset: decay curves of 100 and $10 \mathrm{~nm} \mathrm{EuPO}_{4}$ nanocrystals at 10 and $293 \mathrm{~K}$. of energy migration processes. Decay curve for $10 \mathrm{~nm}$ $\mathrm{EuPO}_{4}$ nanocrystal was close to single exponential at $10 \mathrm{~K}$ and in contrast to $100 \mathrm{~nm} \mathrm{EuPO} 4$ nanocrystals increase of the temperature did not led to any sufficient decrease of decay time. So, energy migration to quenching sites via $\mathrm{Eu}^{3+}$ sublattice becomes less efficient for small $\mathrm{EuPO}_{4}$ nanocrystals.

This effect, however, can be explained taking into account the influence of the nanocrystal size on the phonon spectra [22] and peculiarities of energy migration via $\mathrm{Eu}^{3+}$ ions revealed before [15,29]. Luminescence spectra of $10 \mathrm{~nm} \mathrm{EuPO} 4$ nanocrystals are characterized by sufficient inhomogeneous broadening of $\mathrm{Eu}^{3+}$ spectral lines as compared to the luminescence spectra of $100 \mathrm{~nm}$ nanocrystals (Fig. 8). Increase of the spectral width of $\mathrm{Eu}^{3+}$ lines for $10 \mathrm{~nm}$ nanocrystals can be determined by high number of $\mathrm{Eu}^{3+}$ ions with irregular coordination (first of all, near-surface $\mathrm{Eu}^{3+}$ ions and $\mathrm{Eu}^{3+}$-oxygen vacancy complexes). As was mentioned before, the processes of energy migration in $100 \mathrm{~nm} \mathrm{EuPO} 4$ nanocrystals are phononassisted ones due to absence of resonance between energy levels of adjacent $\mathrm{Eu}^{3+}$ ions. Role of lattice phonons is even higher for $10 \mathrm{~nm} \mathrm{EuPO} 4$ nanocrystals, for which inhomogeneous broadening is sufficient (so, the energy mismatch between adjacent $\mathrm{Eu}^{3+}$ ions can be in the range of few tens $\mathrm{cm}^{-1}$ ).

Phonon-assisted energy transfer processes in which energy migration requires lattice phonons can be sufficiently affected by the modification of phonon density of states (PDOS) in nanocrystals [22]. Analysis of the possible vibrational modes for the finite sphere [32,33] has shown the presence of so-called cutoff frequency in the phonon spectra (leading to absence of low-energy vibrational modes) and modification of PDOS spectra as a whole. Experimental evidences of the influence of phonon spectra modification on the energy relaxation processes were obtained recently for nanoparticles with sizes $20 \mathrm{~nm}$ and less $[16,17]$. The effect of size restriction on the energy migration in $\mathrm{EuPO}_{4}$ nanocrystals observed in our research can be ascribed to modification of phonon spectra as well. As the energy positions of ${ }^{5} D_{0}$ level for $\mathrm{Eu}^{3+}$ ions differ from site to site, participation of phonons in energy migration is crucial and absence of phonon modes required for phononassisted energy transfer between these ions can lead to hampering of energy migration processes. So, the observed decay curves for $10 \mathrm{~nm} \mathrm{EuPO}_{4}$ nanocrystals remained close to single exponential in the wide temperature range.

\section{Conclusions}

Investigation of excitation energy migration in europium phosphate nanocrystals with different sizes and arrangement of regular ions has shown that the processes of energy migration are sufficiently dependent on both these characteristics. Stronger quenching of ${ }^{5} D_{0}$ luminescence of 
$\mathrm{Eu}^{3+}$ ions observed for $\mathrm{EuPO}_{4}: \mathrm{Nd}^{3+}$ nanocrystals as compared with $\mathrm{EuP}_{3} \mathrm{O}_{9}: \mathrm{Nd}^{3+}$ nanocrystals is ascribed to different mechanisms of energy transfer between $\mathrm{Eu}^{3+}$ ions in these structures. Excitation energy migration for both $\mathrm{EuPO}_{4}$ and $\mathrm{EuP}_{3} \mathrm{O}_{9}$ nanocrystals requires participation of low-energy phonons. In this way, decrease of the size of $\mathrm{EuPO}_{4}$ nanocrystal to $10 \mathrm{~nm}$ leads to hampering of excitation energy migration due to the depletion of phonon spectra from the lower-frequency side for $10 \mathrm{~nm}$ nanoparticle.

1. H. Chen, G.D. Wang, Y.J. Chuang, Z. Zhen, X. Chen, P. Biddinger, and J. Xie, Nano Lett. 15, 2249 (2015).

2. S.L. Yefimova, T.N. Tkacheva, P.O. Maksimchuk, I.I. Bespalova, K.O. Hubenko, V.K. Klochkov, A.V. Sorokin, and Yu.V. Malyukin, J. Lumin. 192, 975 (2017).

3. M. Epple, K. Ganesan, R. Heumann, J. Klesing, A. Kovtun, S. Neumann, and V. Sokolova, J. Mater. Chem. 20, 18 (2010).

4. V. Uskoković and D.P. Uskoković, J. Biomed. Mater. Res. 96, 152 (2011).

5. G. Bao, S. Mitragotri, and S. Tong, Annu. Rev. Biomed. Eng. 15, 253 (2013).

6. I. Roy, S. Mitra, A. Maitra, and S. Mozumdar, Int. J. Pharm. 250, 25 (2003).

7. E.I. Altınoglu, T.J. Russin, J.M. Kaiser, B.M. Barth, P.C. Eklund, M. Kester, and J.H. Adair, ACS Nano 2, 2075 (2008)

8. P.A.M. Berdowski and G. Blasse, J. Lumin. 29, 243 (1984).

9. M. Buijs and G. Blasse, J. Lumin. 34, 263 (1986).

10. V.M. Kenkre, Exciton Dynamics in Molecular Crystals and Aggregates, Springer, Berlin, Heidelberg (1982).

11. A.A. Avedeenko, V.A. Karachevtsev, and Y.V. Naboikin, J. Appl. Spectrosc. 46, 377 (1987).

12. V.V. Seminko, A.A. Masalov, Y.I. Boyko, and Y.V. Malyukin, J. Lumin. 132, 2443 (2012).

13. V.V. Seminko, A.A. Masalov, Y.I. Boyko, and Y.V. Malyukin, Opt. Mater. 34, 1998 (2012).

14. V.V. Seminko, P.O. Maksimchuk, N.V. Kononets, A.A. Masalov, Yu.I. Boyko, and Y.V. Malyukin, Funct. Mater. 19, 309 (2012).

15. M. Buijs, A. Meyerink, and G. Blasse, J. Lumin. 37, 9 (1987).
16. K.S. Sohn, Y.Y. Choi, H.D. Park, and Y.G. Choi, J. Electrochem. Soc. 147(6), 2375 (2000).

17. A.J. De Vries, H.S. Kiliaan, and G. Blasse, J. Solid State Chem. 65(2), 190 (1986).

18. Y.V. Malyukin, A.A. Masalov, P.N. Zhmurin, N.V. Znamenskii, E.A. Petrenko, and T.G. Yukina, Phys. Status Solidi B 240(3), 655 (2003).

19. Y. Guyot, R. Moncorge, L.D. Merkle, A. Pinto, B. McIntosh, and H. Verdun, Opt. Mater. 5(1-2), 127 (1996).

20. H. Meyssamy, K. Riwotzki, A. Kornowski, S. Naused, and M. Haase, Adv. Mater. 11(10), 840 (1999).

21. K. Riwotzki, H. Meyssamy, H. Schnablegger, A. Kornowski, and M. Haase, Angew. Chem. Int. Ed. 40(3), 573 (2001).

22. X.Y. Chen, H.Z. Zhuang, G.K. Liu, S. Li, and R.S. Niedbala, J. Appl. Phys. 94(9), 5559 (2003).

23. G.K. Liu, H.Z. Zhuang, and X.Y. Chen, Nano Lett. 2(5), 535 (2002).

24. Y.V. Malyukin, A.A. Masalov, and P.N. Zhmurin, Opt. Commun. 239(4), 409 (2004).

25. P.O. Maksimchuk, A.A. Masalov, V.V. Seminko, O.G. Viagin, V.K. Klochkov, and Y.V. Malyukin, Ukr. J. Phys. 57(2), 193 (2012).

26. N.V. Kononets, V.V. Seminko, P.O. Maksimchuk, A.V. Aslanov, I.I. Bespalova, A.A. Masalov, and Y.V. Malyukin, Fiz. Nizk. Temp. 43, 1252 (2017) [Low Temp. Phys. 43, 1009 (2017)].

27. V.K. Klochkov, N.S. Kavok, Y.V. Malyukin, A.A. Masalov, and O.G. Vyagin, Funct. Mater. 16(4), 466 (2009).

28. H.Y.-P. Hong, Acta Cryst. B 30, 468 (1974).

29. M. Buijs and G. Blasse, J. Lumin. 39(6), 323 (1988).

30. D.F. Mullica, A.D. Grossie, and L.A. Boatner, Inorg. Chim. Acta 109(2), 105 (1985).

31. B. Henderson and G.F. Imbusch, Optical Spectroscopy of Inorganic Solids, Oxford University Press, London (2006), Vol. 44.

32. H. Lamb, Proceedings of the London Mathematical Society 1(1), 189 (1881).

33. A. Tamura, K. Higeta, and T. Ichinokawa, J. Phys. Chem. C: Solid State Phys. 15(24), 4975 (1982). 